\title{
Overexpression of RNF38 facilitates TGF- $\beta$ signaling by Ubiquitinating and degrading AHNAK in hepatocellular carcinoma
}

\author{
Rui Peng ${ }^{1,2+}$, Peng-Fei Zhang ${ }^{1,3+}$, Xuan Yang ${ }^{1 \dagger}$, Chuan-Yuan Wei ${ }^{1+}$, Xiao-Yong Huang ${ }^{1}$, Jia-Bin Cai ${ }^{1}$, Jia-Cheng Lu ${ }^{1}$, \\ Chao Gao ${ }^{1}$, Hai-Xiang Sun ${ }^{1}$, Qiang Gao ${ }^{1}$, Dou-Sheng Bai ${ }^{2}$, Guo-Ming Shi ${ }^{{ }^{*}}$, Ai-Wu Ke ${ }^{1 *}$ and Jia Fan ${ }^{1,4^{*}}$
}

\begin{abstract}
Background: RING finger protein 38 (RNF38), a member of the RNF protein family, has just emerged as a vital driver of cancer progression. However, the oncogenic mechanisms of RNF38 remain unexplored.

Methods: Using frozen tumor tissue and tissue microarray from hepatocellular carcinoma (HCC) patients, we tried to probe the expression of RNF38 in HCC and its clinical value. Then the biological functions of RNF38 were analyzed in vivo and vitro. Stable isotope labeling with amino acids (SILAC) in cell culture and co-immunoprecipitation proteomic analyses were combined to reveal the potential mechanism of RNF38 in HCC progression.

Results: We report that RNF38 expression was markedly higher in HCC tissues than in peritumor tissues. Correspondingly, RNF38 overexpression promoted the HCC cell migration and invasion and inhibited apoptosis both in vitro and in vivo. And elevated RNF38 expression induced HCC cell epithelial-mesenchymal transition by facilitating transforming growth factor- $\beta$ (TGF- $\beta$ ) signaling via ubiquitinating and degrading neuroblast differentiation-associated protein (AHNAK), a well-established inhibitor of TGF- $\beta$ signaling. Furthermore, AHNAK interference restored the HCC cell invasion and metastasis deprived by RNF38 downregulation. Clinically, elevated RNF38 and transforming growth factor beta receptor 1 (TGFBR1) expression was related to short overall survival (OS) and high cumulative recurrence rates in HCC patients.
\end{abstract}

Conclusions: High levels of RNF38 promote HCC by facilitating TGF- $\beta$ signaling and are a novel marker for predicting the prognosis of HCC patients and a potential therapeutic target in HCC.

Keywords: Hepatocellular carcinoma, RNF38, AHNAK, TGF- $\beta$ signaling, Prognosis

\section{Introduction}

Hepatocellular carcinoma (HCC) is still among the leading causes of cancer-related death worldwide, especially in China $[1,2]$. The high rate of relapse and early invasion and metastasis are the major reasons for the poor outcomes of HCC patients. Currently, except for curative surgical therapy, effective means of controlling HCC progression are lacking. During the past decade, targeted drugs

\footnotetext{
* Correspondence: shi.guoming@zs-hospital.sh.cn; ke.aiwu@zs-hospital.sh.cn; fanjia-zs@hotmail.com

${ }^{\dagger}$ Rui Peng, Peng-Fei Zhang, Xuan Yang and Chuan-Yuan Wei contributed equally to this work.

'Liver Cancer Institute, Zhongshan Hospital, Fudan University; Key Laboratory of Carcinogenesis and Cancer Invasion (Fudan University), Ministry of Education, 180 Feng lin Road, Shanghai 200032, People's Republic of China Full list of author information is available at the end of the article
}

such as sorafenib and regorafenib have been put into clinical use [3]. However, most patients realize a limited benefit due to drug resistance [4]. Thus, revealing the molecular mechanism of $\mathrm{HCC}$ progression and identifying new key markers or targets for the diagnosis and treatment of $\mathrm{HCC}$ patients is extremely urgent.

Ubiquitination is a complex yet significant process that controls a vast array of cellular functions, including cell metabolism, survival, differentiation, as well as the cell cycle. Among the multiple steps in the ubiquitination process, E3 ubiquitin ligases (E3s) control precise substrate recognition by mediating the transfer of ubiquitin from E2-ubiquitin-binding enzymes (E2s) to substrates, and thus govern the fate or subcellular localization of ubiquitinated proteins [5]. E3s are frequently dysregulated in

(C) The Author(s). 2019 Open Access This article is distributed under the terms of the Creative Commons Attribution 4.0 International License (http://creativecommons.org/licenses/by/4.0/), which permits unrestricted use, distribution, and 
tumors, resulting in the dysfunction of tumor suppressor genes or oncogenes which further participate in cellular transformation or tumor progression [6, 7]. RING finger (RNF) proteins, the largest class of E3s with RNF domains containing eight conserved cysteine and histidine residues, play various roles in human physiology and pathologies [8], especially cancer progression [9]. For example, RNF43 frequently mutates in colorectal and endometrial cancers [10] and in liver fluke-associated cholangiocarcinoma [11]. RNF38, a member of the RNF protein family, is abundant in the human testis, and its dysfunction is involved in a variety of human disorders, particularly neoplasms [12]. Indeed, the human RNF38 gene is located on the short arm of chromosome 9, which is a region enriched with drivers of chronic myelogenous leukemia (CML) $[13,14]$. Additionally, RNF38 was identified to ubiquitinate TP53 in HEK293T cells [15], and upregulated RNF38 expression was recently found to promote non-small cell lung cancer cell invasion and metastasis by inducing cell epithelialmesenchymal transition (EMT) [16]. Thus, there is a growing need to determine the detailed molecular mechanism of RNF38 in cancer.

In this study, we aimed to determine the expression of RNF38 in HCC tissues and the potential prognostic value of RNF38, particularly the definitive mechanism by which RNF38 induces the invasion and metastasis of HCC.

\section{Methods and materials}

\section{Patients samples and follow up}

A total of $200 \mathrm{HCC}$ patients who underwent complete surgical excision between January 2006 and December 2008 at Zhongshan Hospital Fudan University (Shanghai, China) were enrolled randomly in the study. The diagnosis of HCC was confirmed independently by two pathologists. Neoplastic and matched normal tissues were obtained after surgery and were further used for tissue microarray (TMA) construction. The fresh tumor samples were acquired from Zhongshan Hospital (Shanghai, China). The study was approved by the Institutional Review Board of Zhongshan Hospital Fudan University, and informed consent was obtained from the patients prior to the study.

\section{Immunohistochemistry (IHC), immunoblot (IB), and real-}

\section{time quantitative PCR (qRT-PCR) analyses}

The IHC protocol and qualitative criteria for the intensity of staining were used as shown in our previous study [17]. And the IHC details were listed in the Additional file 1 . The integrated optical density (IOD) values were assessed by Image-Pro Plus software. IB analysis was performed in our earlier study [18]. Relative protein expression was analyzed by Image J software. The information for the primary antibodies was listed in Additional file 2: Table S1. For qRT-PCR, RNA was extracted from tissue or cell lines as previously described [19], with SYBR Green Realtime PCR
Master Mix (Yeasen, Shanghai, China). The PCR primers used were as follows: RNF38, forward: 5'-AACACGGAG AGCAGTTCCAC-3' and reverse: 5'-CCTGGCATACGT CTTCAACA-3'. GAPDH, forward: 5'-GGTATGACAAC GAATTTGGC-3' and reverse: 5'-GAGCACAGGGTACT TTATTG-3'. AHNAK, forward: 5'-GAGGTCTTCCAGG CATTGGTGTTC-3' and reverse: 5'-GGCAGGTTCA CA TCACATCCAGAG-3'. TGFBR1, forward: 5'-GCAGAGC TGTGAAGCCTTGAGAG-3' and reverse: $5^{\prime}$ - ATGCCTT CCTGTTGACTGAGTTGC-3'.

\section{Cell lines and transfection}

The human HCC cell lines HCCLM3, Huh7, PLC/PRF/ 5, and HepG2 were obtained from the Chinese Academy of Science Cell Bank (Shanghai, China). All cell lines were cultured in DMEM supplemented with $10 \%$ fetal bovine serum and $1 \%$ antibiotics at $37{ }^{\circ} \mathrm{C}$ in a humidified incubator with $5 \% \mathrm{CO}_{2}$.

All vectors were purchased from Shanghai Genomeditech Company (Shanghai, China). The HCCLM3 cell line was transfected with RNF38 short hairpin RNA (shRNA) lentiviral vectors and the corresponding control vectors, and the HepG2 cell line was transfected with RNF38 cDNA lentiviral vectors and the corresponding control vectors. The AHNAK small interfering RNA (siRNA) was also constructed by Shanghai Genomeditech Company (Shanghai, China). The RNF38 shRNA target sequences were as follows: shRNA1: 5' - GUCUCGACAUAAUUCCAUU-3', shRNA2: 5'-CAUGGGAGAUGACAUCAAA-3'. The AH NAK siRNA target sequences were as follows: siRNA1, forward, 5'-CUGCUGCUGCCCAACUGGC tt-3', reverse, 5'-GCCAGUUGGGCAGCAGCAGtt-3'; siRNA2, forward, 5'-GGCGUCUUGUGC AGGAGGtt-3', reverse, 5' -CCUC CUGCACAAAGACGCCtt-3'; siRNA3, forward, 5'-GCUG CC CAACUGGCAGGGUtt-3', reverse, 5' ACCCUGCCA GUUGGGCAGCtt-3'. The antibiotic-resistant transfected cells were selected by adding puromycin to the culture medium for 7 days.

\section{Cell migration, Matrigel invasion, and cell proliferation assays}

The cell migration and matrigel invasion assays were performed as described in our previous report [20]. For the cell proliferation assay, $2 \times 10^{3}$ cells were incubated in 96-well plates, and at the prescribed time, the OD value was determined by a cell counting kit-8 (CCK-8) assay (Yeasen, Shanghai, China).

\section{Immunofluorescent staining and flow cytometry assays}

Immunofluorescence staining was performed as described in our previous study [21]. Flow cytometric analysis was performed to calculate the rate of HCC cell apoptosis. The cell samples were stained with annexin V-FITC/PI, cells in the lower-right quadrant were Annexin $\mathrm{V}$ positive 
and defined as early apoptotic cells, and cells in the upper-right quadrant were Annexin V positive and PI positive and defined as late apoptotic cells. Both quadrants were included to evaluate the capability of the cells to resist apoptosis.

\section{Tumor growth in vivo}

Four-week-old nude mice were acquired from the Shanghai Institute of Material Medicine and were raised in the specific pathogen-free animal laboratory. A total of $5 \times 10^{6}$ HCC cells were injected to generate subcutaneous tumors in the nude mice. Tumor growth was measured every 5 days after the injection until the 32nd day. Tumors were measured in two dimensions, as described in our earlier study [20]. Serial sections of mice lungs were stained with $\mathrm{H} \& \mathrm{E}$, and the metastatic rate was calculated as previously described [21]. The Mice experiments conformed to the requirements of the Animal Ethics Committee of Zhongshan Hospital, Fudan University.

\section{Coimmunoprecipitation (co-IP)}

First, cold RIPA lysis buffer (50 mM Tris (pH 7.4), $150 \mathrm{mM}$ $\mathrm{NaCl}, 1 \%$ Triton $\mathrm{X}-100,1 \%$ sodium deoxycholate, and $0.1 \%$ SDS) containing $1 \mu \mathrm{m}$ complete protease inhibitor (Roche) was added to cultured cells. Next, the mixture was placed on a low-speed rotating shaker for $30 \mathrm{~min}$ at $4{ }^{\circ} \mathrm{C}$. Then, the supernatant was transferred to new tubes after centrifugation at $13,000 \mathrm{~g}$ and $4{ }^{\circ} \mathrm{C}$ for $15 \mathrm{~min}$. Subsequently, the precleared lysates were incubated with primary antibody (RNF38, 1:100; AHNAK, 1:100 or, IgG (homologous control antibody) 1:100) preabsorbed protein A- and G-sepharose beads overnight at $4{ }^{\circ} \mathrm{C}$. The precipitates were cleaned with the RIPA buffer three times. The whole immunoprecipitates were boiled in $1 \times$ SDS loading buffer (Beyotime, P0015A) for $5 \mathrm{~min}$, and the proteins were resolved by SDS-PAGE on $10 \%$ separating gel. Finally, immunoblots were probed with the appropriate antibody and detected by ECL.

\section{Stable isotope labeling by amino acids in cell culture (SILAC)}

Briefly, HepG2-NC cells were maintained in normal DMEM nutrient medium with $10 \%$ FBS, which is called light from here on. And HepG2-RNF38 cells maintained with nutrient media containing L-lysine-2 $\mathrm{HCl}\left({ }^{13} \mathrm{C}_{6},{ }^{15} \mathrm{~N}_{2}\right)$ (Thermo Scientific ${ }^{\mathrm{mm}}, 88,432$ ), which is deemed to be heavy from here on. The reverse reaction was set up under the same conditions, but HepG2-NC cells were maintained in heavy acid and HepG2-RNF38 were maintained in light acid. The whole system was cultivated in the SILAC medium for 10 passages to achieve full labeling before harvesting. The cells were lysed by modified RIPA buffer $(50 \mathrm{mM}$ Tris- $\mathrm{HCl}, \mathrm{pH} 7.8,150 \mathrm{mM} \mathrm{NaCl}, 1 \% \mathrm{NP}-40$, $0.25 \%$ sodium deoxycholate and $1 \mathrm{mM}$ EDTA) [22] and mixed in a one to one ratio. The lytic cells were centrifuged in $4{ }^{\circ} \mathrm{C}$. The supernatant was aspirated, and the mixture lysate was digested by trypsin, and fractionated by high-performance liquid chromatography (HPLC) and analyzed by LC-MS/MS. For these two reactions, we calculated the ratio of light to heavy or heavy to light peptides. And a 1.5 fold change cutoff for the peptide prophet probability used to filter the dataset. And the detail of defferential proteins are listed in Additional file 3: Table S2 and Additional file 4: Table S3

\section{Liquid chromatography coupled with tandem mass spectrometry (LC-MS/MS)}

Immunoprecipitates or SILAC mixture was subjected to LC-MS/MS (Q-Extacive Plus, Thermo Scientific) analysis. The details of the LC-MS/MS method are described in the Additional file 1.

\section{Ubiquitination assay and cycloheximide ( $\mathrm{CHX})$ chase assay}

For the ubiquitination assay, HCCLM3-NC and HCCLM3-shRNA2 cells were treated with MG132 ( $5 \mu \mathrm{mol}$, Selleck, China). Next, these two cell lines were subjected to co-IP and the IB analysis was used to detect ubiquitin. For $\mathrm{CHX}$ chase assay was used to observe the half-life of AHNAK. HCCLM3-NC and HCCLM3-shRNA2 cells were treated with CHX $(50 \mu \mathrm{g} /$ $\mathrm{mL}$ ) for the indicated times, and IB was performed.

\section{Statistical analysis}

SPSS software 21.0 was used for statistical analyses. Student's t-test was used to compare quantitative data between two groups. The relationship between the two proteins was assessed by the Pearson correlation coefficient. The Kaplan-Meier method and the log-rank test were used to analyze the overall survival and cumulative recurrence rate. $p<0.05$ was considered statistically significant.

\section{Results}

RNF38 is overexpressed in HCC tissues and associated with poor prognosis in $\mathrm{HCC}$ patients

We first examined the levels of RNF38 protein and mRNA in 36 pairs of HCC and adjacent nontumor tissues and found that the RNF38 protein expression was higher in HCC tissues than in normal tissues (Fig. 1a, $p=0.033$ ). This finding was also true for the mRNA expression (Fig. $1 \mathrm{~b}, p=0.036$ ). These results were consistent with those availabe in a public database (www.oncomine.org), that showed that RNF38 was overexpressed in several gastrointestinal cancers (Additional file 5: Figure S1 A-D). IHC staining of tissues from $200 \mathrm{HCC}$ patients showed that RNF38 expression was significantly higher in tumors than in peritumor tissues (Fig. 1c, left panel). Moreover, the RNF38 expression in HCC samples was considerably 
A
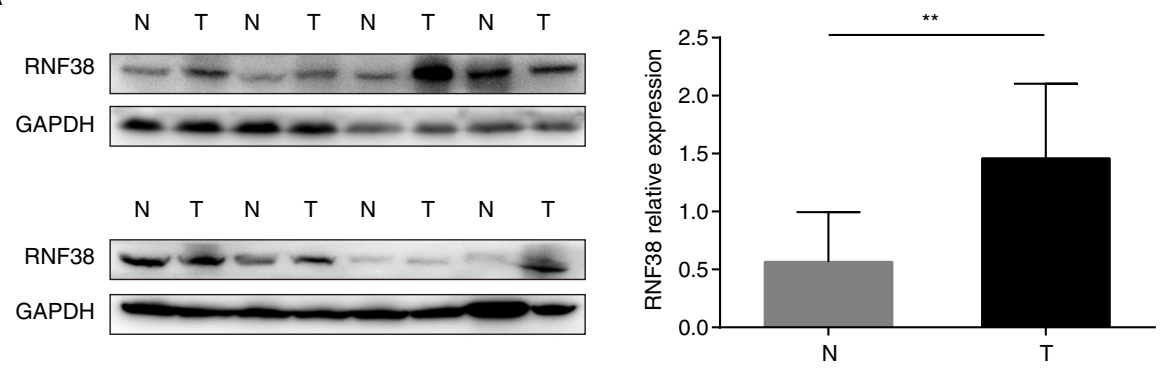

B
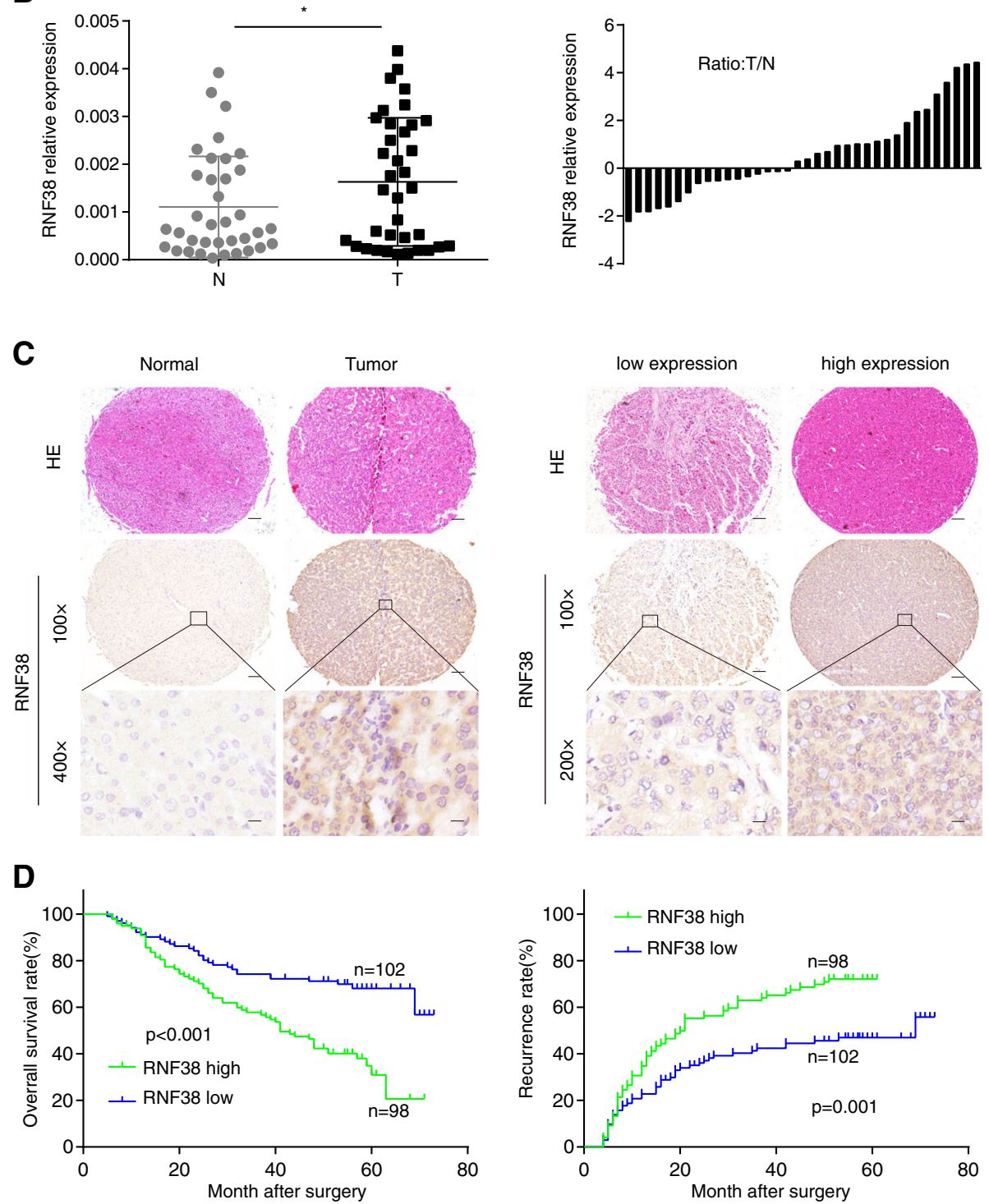

Fig. 1 RNF38 is overexpressed in HCC patients and associated with HCC patients' poor prognosis. a. The expression of RNF38 protein in HCC tumor tissues and matched normal tissues was verified by western blot. b. The expression of RNF38 mRNA was verified by qRT-PCR. c. The expression of RNF38 was measured by IHC in TMAs including 200 HCC patients, and typical photos were presented. $\mathbf{d}$. Prognostic analysis of RNF38 expression in 200 HCC patients. Scale bar: $100 \mu \mathrm{m}$. ${ }^{*}, p<0.05$ 
variable among patients (Fig. 1c, right panel). Further analyses indicated that high levels of RNF38 expression were significantly correlated with large tumor size $(p=0.008)$, the absence of tumor encapsulation $(p=0.004)$, the presence of embolus $(p=0.030)$, and advanced TNM stage $(p=0.019$, Table 1$)$. Moreover, patients with high RNF38 expression $(n=98)$ had shorter survival times and a high rate of recurrence than those with low RNF38 expression ( $n=102$, Fig. 1e). Importantly, Cox regression analysis indicated that tumor size, embolus, and the RNF38 staining level are independent prognostic factors for HCC patients (Table 2). All in all, these results suggest that RNF38 could be a key promoter of HCC progression.

High levels of RNF38 promote HCC cell motility, and invasion and inhibit HCC cell apoptosis both in vitro and in vivo

To understand the effect of RNF38 on HCC development, we determined the RNF38 expression in four HCC cell lines (Fig. 2a) and transfected RNF38 shRNA into HCCLM3 cells and RNF38 vectors into HepG2 cells. Stable expression of RNF38 was confirmed by western blotting and qRT-PCR (Fig. 2b). The CCK- 8 assay revealed that RNF38 knockdown inhibited the HCC cell growth rate (Fig. 2c, both $p<0.001$,). Moreover, the migration and invasion assays showed that overexpression of RNF38 promoted the motility of HCC cells (Fig. $2 \mathrm{~d}, p<0.001$ and Fig. 2e, $p<0.001, p=0.0046$ ). Furthermore, flow cytometry indicated that RNF38 downregulation enhanced the rate of apoptosis inhibition (Fig. 2f, $p=0.0121, p=$ 0.0076). Subsequently, a subcutaneous xenograft model was established to analyze the function of RNF38 in vivo. One week after inoculation, tumors were palpable, and the growth curve suggested that HCCLM3-NC cells $\left(398.32 \pm 16.85 \mathrm{~mm}^{3}\right)$ exhibited higher proliferation ability than HCCLM3-shRNA2 cells $\left(217.79 \pm 19.69 \mathrm{~mm}^{3}\right)$. In contrast, HepG2-RNF38 cells group $(671.43 \pm 107.14$ $\mathrm{mm}^{3}$ ) had a higher proliferative ability than HepG2-NC cells $\left(170.43 \pm 37.96 \mathrm{~mm}^{3}\right.$, Fig. $2 \mathrm{~g}$ and $\left.\mathrm{h}\right)$. Moreover, the lung metastasis rate was examined by H\&E staining (Fig. $2 \mathrm{i}$, upper panel), and the results showed that the Incidence of pulmonary metastasis was $80 \%$ (4 of 5 ) in the group of animals injected with HCCLM3-NC cells, which markedly higher than that in the HCCLM3-shRNA2 group (20\%, 1 of 5). Furthermore, the metastasis rate was $0 \%$ (0 of 5 ) in HepG2-NC group, and $100 \%$ (5 of 5) in the HepG2RNF38 group. (Fig. 2i, lower panel).

\section{High levels of RNF38 induce EMT in HCC cells}

The role of EMT in cancer metastasis is now widely accepted [23]. Here, we found that HCCLM3-shRNA2 and HepG2-NC cells joined closely like epithelial cells, while the other two groups of cells appeared spindle-like, and fibroblastic (Fig. 3a). Next, we determined the levels of
Table 1 Correlation between RNF38 and clinicopathological characteristics in 200 HCC patients

\begin{tabular}{|c|c|c|c|}
\hline \multirow[t]{2}{*}{ Variables } & \multicolumn{2}{|c|}{ Number of patients } & \multirow[b]{2}{*}{$P$ value } \\
\hline & RNF38 high & RNF38 ${ }^{\text {low }}$ & \\
\hline \multicolumn{4}{|l|}{ Gender } \\
\hline Female & 12 & 15 & \multirow[t]{2}{*}{0.611} \\
\hline Male & 86 & 87 & \\
\hline \multicolumn{4}{|l|}{ Year } \\
\hline$<52$ & 43 & 53 & \multirow[t]{2}{*}{0.253} \\
\hline$\geq 52$ & 55 & 49 & \\
\hline \multicolumn{4}{|c|}{ Hepatic cirrhosis } \\
\hline Yes & 87 & 91 & \multirow[t]{2}{*}{0.921} \\
\hline No & 11 & 11 & \\
\hline \multicolumn{4}{|l|}{ HbsAg } \\
\hline Positive & 79 & 86 & \multirow[t]{2}{*}{0.491} \\
\hline Negtive & 19 & 16 & \\
\hline \multicolumn{4}{|l|}{$\mathrm{HCV}$} \\
\hline Positive & 0 & 2 & \multirow[t]{2}{*}{$0.498^{\mathrm{a}}$} \\
\hline Negtive & 98 & 100 & \\
\hline \multicolumn{4}{|l|}{ AFP } \\
\hline$<20$ & 33 & 43 & \multirow[t]{2}{*}{0.217} \\
\hline$\geq 20$ & 65 & 59 & \\
\hline \multicolumn{4}{|c|}{ Tumor size (cm) } \\
\hline$<5$ & 46 & 67 & \multirow[t]{2}{*}{$0.008\left(^{* *}\right)$} \\
\hline$\geq 5$ & 52 & 35 & \\
\hline \multicolumn{4}{|c|}{ Tumor number } \\
\hline Single & 83 & 85 & \multirow[t]{2}{*}{0.793} \\
\hline Multiple & 15 & 17 & \\
\hline \multicolumn{4}{|c|}{ Tumor encapsulation } \\
\hline Complete & 61 & 43 & \multirow[t]{2}{*}{$0.004(* *)$} \\
\hline None & 37 & 59 & \\
\hline \multicolumn{4}{|c|}{ Tumor differentiation } \\
\hline$I+\|$ & 66 & 79 & \multirow[t]{2}{*}{0.110} \\
\hline III + IV & 32 & 23 & \\
\hline \multicolumn{4}{|c|}{ Edmondson-Steiner Grade } \\
\hline $1+\|$ & 58 & 62 & \multirow[t]{2}{*}{0.817} \\
\hline III & 40 & 40 & \\
\hline \multicolumn{4}{|l|}{ Embolus } \\
\hline Absence & 60 & 77 & \multirow[t]{2}{*}{$0.030\left(^{*}\right)$} \\
\hline Present & 38 & 25 & \\
\hline TNM stage & & & \\
\hline 1 & 61 & 79 & $0.019(*)$ \\
\hline$\|+\| \|$ & 37 & 23 & \\
\hline
\end{tabular}


Table 2 Univariate and multivariate analyses of factors associated with overall survival and cumulative recurrence

\begin{tabular}{|c|c|c|c|c|c|c|c|c|}
\hline \multirow[t]{3}{*}{ Factors } & \multicolumn{4}{|c|}{ overall survival } & \multicolumn{4}{|c|}{ cumulative recurrence } \\
\hline & \multicolumn{2}{|c|}{ Univariate } & \multicolumn{2}{|l|}{ Mulvariate } & \multicolumn{2}{|c|}{ Univariate } & \multicolumn{2}{|l|}{ Mulvariate } \\
\hline & $P$ value & $H R$ & $95 \% \mathrm{Cl}$ & $P$ value & $P$ value & $\mathrm{HR}$ & $95 \% \mathrm{Cl}$ & $P$ value \\
\hline Gender (Female vs. Male) & 0.060 & & & NA & 0.127 & & & NA \\
\hline Age (years) ( $\geq 53$ vs. $<53$ ) & 0.888 & & & NA & 0.469 & & & NA \\
\hline Liver cirrhosis (yes vs. no) & 0.930 & & & NA & 0.127 & & & NA \\
\hline HBsAg (positive vs. negative) & 0.183 & & & NA & 0.622 & & & NA \\
\hline HCV (positive vs. negative) & 0.983 & & & NA & 0.793 & & & NA \\
\hline Serum AFP, ng/mL ( $\geq 20$ vs. $<20$ ) & 0.065 & & & NA & 0.011 & & & NS \\
\hline Tumor differentiation (III/IV vs. I/II) & 0.197 & & & NA & 0.069 & & & NA \\
\hline Edmondson-Steiner Grade (I/II vs. III) & 0.191 & & & NA & 0.018 & & & NS \\
\hline Tumor encapsulation (yes vs. no) & 0.195 & & & NA & 0.043 & & & NS \\
\hline TNM stage (I/II vs. III/IV) & 0.005 & & & NS & 0.086 & & & NA \\
\hline Tumor size (diameter, $\mathrm{cm}$ ) ( $\geq 5$ vs. $<5$ ) & 0.001 & 1.587 & $1.043-2.414$ & 0.031 & 0.001 & 1.823 & $1.247-2.665$ & 0.002 \\
\hline Embolus (Absence vs. Present) & $<0.001$ & 2.232 & $1.472-3.385$ & $<0.001$ & $<0.001$ & & & NS \\
\hline Tumor number (multiple vs. single) & 0.045 & & & NS & 0.002 & 2.121 & $1.366-3.294$ & 0.001 \\
\hline RNF38 staining (high vs. low) & $<0.001$ & 2.046 & $1.321-3.171$ & 0.001 & 0.001 & 1.642 & $1.117-2.415$ & 0.012 \\
\hline
\end{tabular}

Abbreviations: $95 \% \mathrm{Cl}$ 95\% confidence interval, AFP alpha-fetoprotein, TNM tumor node metastasis, $H B s A g$ hepatitis B surface antigen, $H C V$ hepatitis C virus, $H R$ hazard ratio, NA not adopted, NS not significant

Cox proportional hazards regression model

several EMT markers in cell lines with different RNF38 expression levels and found that the E-cadherin expression was higher in HCCLM3-shRNA2 cells than in HCCLM3NC cells and in HepG2-NC cells than in HepG2-RNF38 cells, while the expression of snail and vimentin was lower in HCCLM3-shRNA2 cells than in HCCLM3-NC cells and in HepG2-NC cells than in HepG2-RNF38 cells (Fig. 3b). Semi-quantitative IB analysis results are shown in Fig. 3c. Furthermore, The EMT phenotype was further confirmed by immunofluorescence (Fig. 3D). Importantly, IHC analysis of the serial sections showed that cancer cells from aggressive margins had higher levels of RNF38, vimentin and snail and loss of E-cadherin in both HCC and transplanted tumor tissues, strongly suggesting that cells with elevated RNF38 expression underwent EMT (Fig. 3e and f). The above results indicate that RNF38 fosters the progression of HCC by inducing EMT in HCC cells.

\section{AHNAK is a substrate of RNF38 in HCC cells}

Here, we performed SILAC to determine the change in total protein in cells with different RNF38 expression levels (Fig. 4a) and found that 518 proteins were upregulated, and 399 proteins were downregulated (Fig. 4b). These results were further confirmed by selecting 8 proteins randomly for western blot analysis (Fig. 4c). The functional analysis indicated that the differentially expressed proteins were enriched primarily in the Gene Ontology (GO) terms of cell migration, transforming growth factor beta receptor pathway, cell cycle, cell proliferation, negative regulation of apoptotic process, cell chemotaxis, and positive regulation of epithelial to mesenchymal transition, and the Kyoto Encyclopedia of Genes and Genomes (KEGG) pathways of cell cycle, central carbon metabolism in cancer, Wnt pathway, proteoglycans in cancer, focal adhesion, regulation of actin cytoskeleton, adherens junction, and TGF- $\beta$ pathway (Fig. 4d). Then, co-IP was used to isolate and identify the interactome of RNF38 in protein lysate from HCC cells expressing high levels of RNF38. In this assay, 58 and 74 proteins were isolated from HCCLM3-NC and HepG2-RNF38 cell lines, respectively (Fig. 4e). In addition, eight proteins including RNF38, AHNAK, tripartite motif containing 21 (TRIM21), dermcidin (DCD), scaffold protein involved in DNA repair (SPIDR), CD109 molecule (CD109), transforming growth factor beta receptor associated protein 1(TGFBRAP1), ubiquitin protein ligase E3 component n-recognin 5(UBR5) overlapped in the two different cell lines (Fig. 4e). Interestingly, TRIM21 and UBR5 are E3 ligases [24, 25], CD109 and TGFBRAP1 are well-known regulators in the TGF- $\beta$ pathway that act as oncogenes $[26$, 27]. Due to the obvious downregulation of AHNAK in cells overexpressing RNF38, we tried to elucidate the relationship between RNF38 and AHNAK protein in HCC cell. Co-IP combined with immunoblotting showed that endogenous RNF38 forms a complex with AHNAK (Fig. 4f) and immunoblotting revealed that although the overexpression of RNF38 resulted in the downregulation of AHNAK protein expression (Fig. 4g), RNF38 expression was not related to AHNAK mRNA expression (Fig. 4h). Additionally, IF analysis showed that the high level of RNF38 was negatively associated with the AHNAK protein level (Fig. 4i). A 


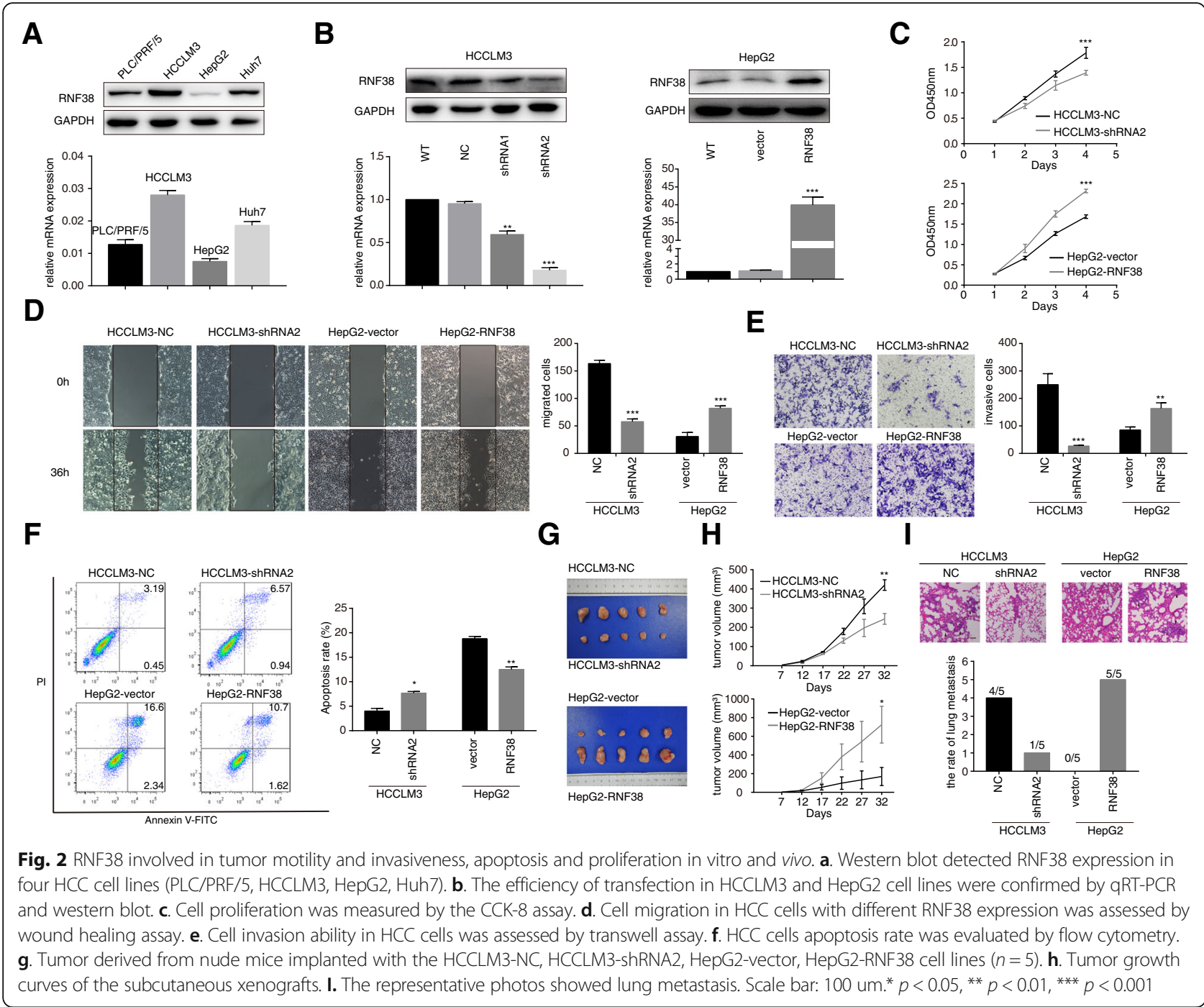

a ubiquitination assay and a $\mathrm{CHX}$ chase assay, indicated a decrease of RNF38 that obviously abrogated the AHNAK ubiquitination after MG132 (5 $\mu \mathrm{mol})$ treatment for $10 \mathrm{~h}$ (Fig. 4j). Furthermore, the physical interaction between RNF38 and AHNAK was examined, the confocal imaging showed that RNF38 (green) and AHNAK (red), whose expression partially overlapping, indicated that they interacted with each other (Additional file 6: Figure S2). Furthermore, the downregulation of RNF38 prolonged the half-life of the AHNAK protein (Fig. 4k). These data suggest that the AHNAK protein is a substrate of RNF38 and that RNF38 promotes AHNAK degradation.

\section{RNF38 facilitates TGF- $\beta /$ Smad2/3 signaling in HCC cells by degrading AHNAK protein}

The SILAC results indicated that the RNF38 might be involved in the TGF- $\beta$ pathway, and previous studies have demonstrated that AHNAK could influence several signaling pathways, especially the TGF- $\beta$ pathway [28-30]. Here, we tried to determine the signaling related to RNF38 expression. As shown in Fig. 5a, the expression of the phosphorylated Drosophila mothers against decapentaplegic protein 2/3 (p-Smad2/3) was reduced by RNF38 knockdown, but there were no significant changes in the expression of phosphorylated AKT or ERK1/2, indicating that a high level of RNF38 might promote HCC progression mainly via TGF- $\beta 1 /$ Smad signaling. Thus, we further determined the role of RNF38 in TGF- $\beta$ pathway. After treating four cell lines with TGF- $\beta 1(5 \mu \mathrm{m})$ for $0 \mathrm{~h}, 2 \mathrm{~h}, 4 \mathrm{~h}, 8 \mathrm{~h}$, we chose the $8 \mathrm{~h}$ as the optimal treatment time for the subsequent study (Fig. 5b). The four cell lines were treated with TGF- $\beta 1(5 \mu \mathrm{m}, 8 \mathrm{~h})$ and/or LY2109761 $(10 \mu \mathrm{m}, 2 \mathrm{~h})$, a TGF- $\beta / \mathrm{smad} 2 / 3$ inhibitor, and we found that compared with the control cells, RNF38 silenced cells showed a decreasing trend in the response to TGF- $\beta$ stimulation, which was rescued by LY2109761 treatment (Fig. 5c). Additionally, to assess whether an increase of AHNAK protein expression by RNF38 knockdown also led to decreased 
A

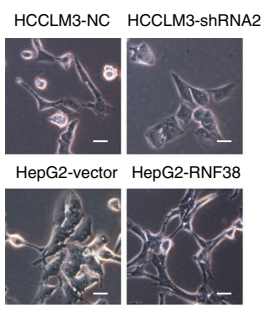

D

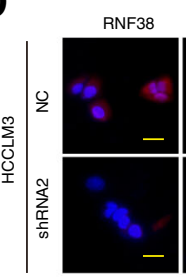

E
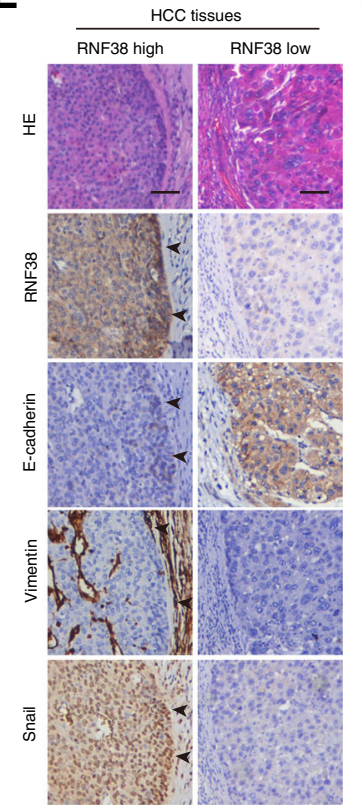

B

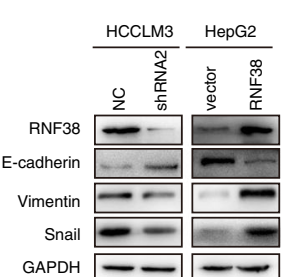

GAPDH $--\infty$

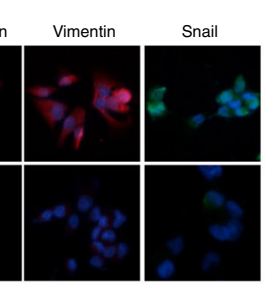

$\mathbf{F}$
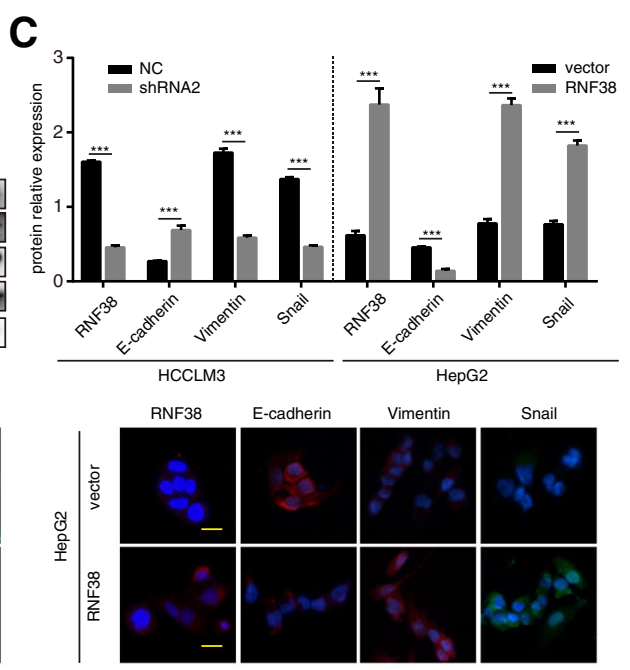

Xenograft tumor tissues

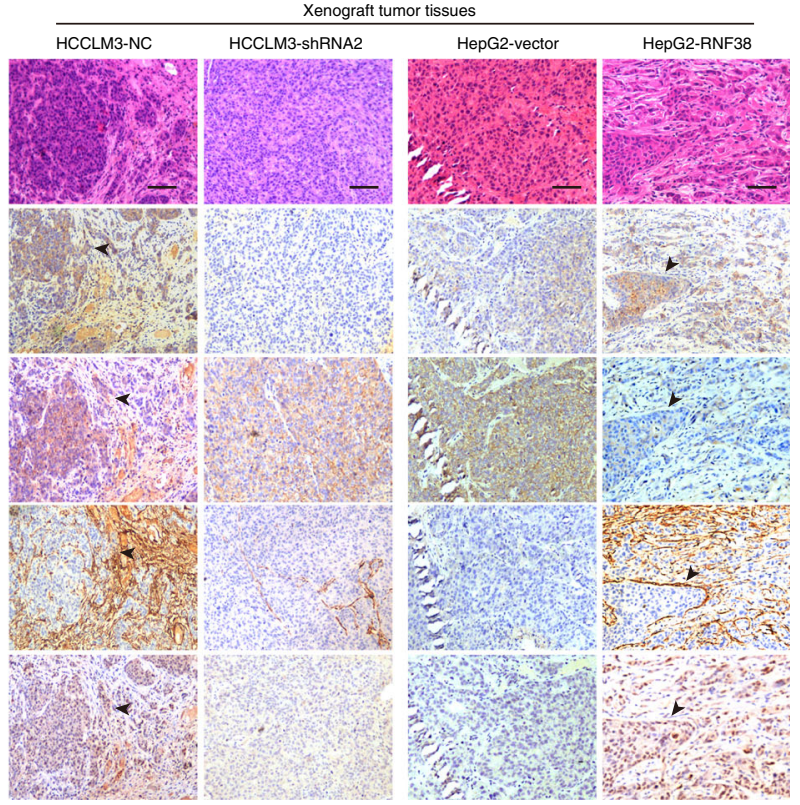

Fig. 3 RNF38 induced HCC cell EMT. a. The cellular morphology of four cell lines (HCCLM3-NC, HCCLM3-shRNA2, HepG2-vector, and HepG2RNF38) was detected by phase contrast microscope. b. Expression of epithelial and mesenchymal markers was compared among HCCLM3-NC, HCCLM3-shRNA2, HepG2-vector, and HepG2-RNF388 cell lines. c. Semi-quantitative analysis of western bolt. d. Representative immunofluorescent images of RNF38, E-cadherin, Vimentin, and $\beta$-catenin in HCCLM3-NC, HCCLM3-shRNA2, HepG2-vector, and HepG2-RNF38 cells. e. Serial section and IHC staining showed expression of RNF38, E-cadherin, Vimenail. f. Xenograft tumor tissues IHC staining showed expression of RNF38, Ecadherin, Vimentin, and Snail. Scale bars $50 \mu \mathrm{m}$. The typical EMT cells are represented as black arrows. ${ }^{*} p<0.05$, $^{* *} p<0.01,{ }^{* * *} p<0.001$

phospho-Smad2/3 levels, we reintroduced siAHNAK in HCCLM3-shRNA2 and compared the phosphorylation level of Smad2/3 among in HCCLM3-NC, HCCLM3shRNA2, and HCCLM3-shRNA2-siAHNAK cells (Additional file 7: Figure S3). Immunoblotting showed that interference of AHNAK restored phospho-smad2/3 levels in RNF38-depleted cells (Fig. 5d). Importantly, the functional test revealed that suppressing AHNAK in HCCLM3shRNA2 cells dramatically restored HCC cell invasiveness (Fig. 5e) and remodeled the cell morphology from epithelial cells to mesenchymal cells (Fig. 5f). These results imply that RNF38 contributes to the invasion and EMT of HCC cells by ubiquitinating and degrading AHNAK to abrogate the inhibition of TGF- $\beta$ signaling (Fig. 6).

\section{RNF38 expression and TGF- $\beta$ signaling in the prognosis of HCC patients}

In most cell types, the canonical TGF- $\beta$ pathway induces Smad phosphorylation via TGFBR1, which is activated by TGFBR 2 upon ligand binding and forms a tetrameric 

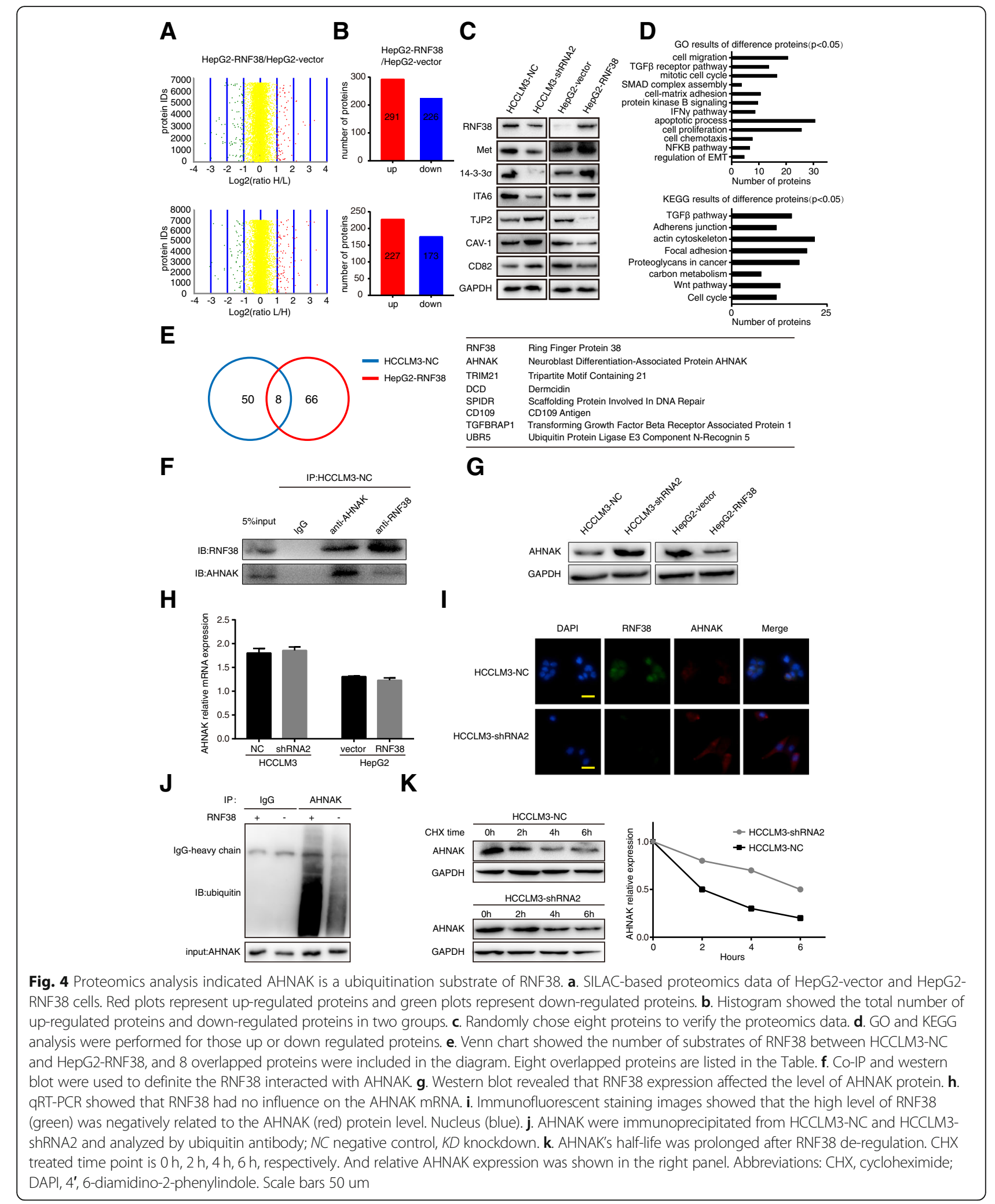

D

receptor heterocomplex with TGFBR2 [31]. To further reveal the role of RNF38 in TGF- $\beta$ signaling in HCC patients, we randomly selected $15 \mathrm{HCC}$ tissues in which determine the expression of RNF38 and TGFBR1, an important molecule in the TGF- $\beta$ pathway, at the protein and mRNA level (Fig. $7 \mathrm{a}$ and $\mathrm{c}$ ), and the Pearson 
A

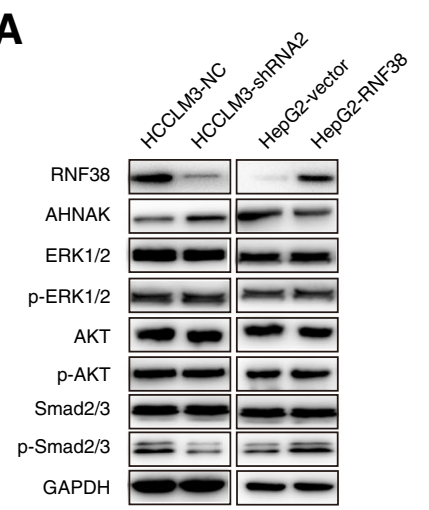

B
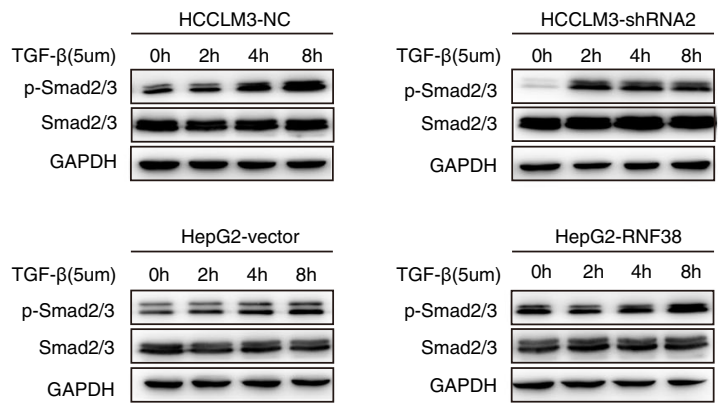

C
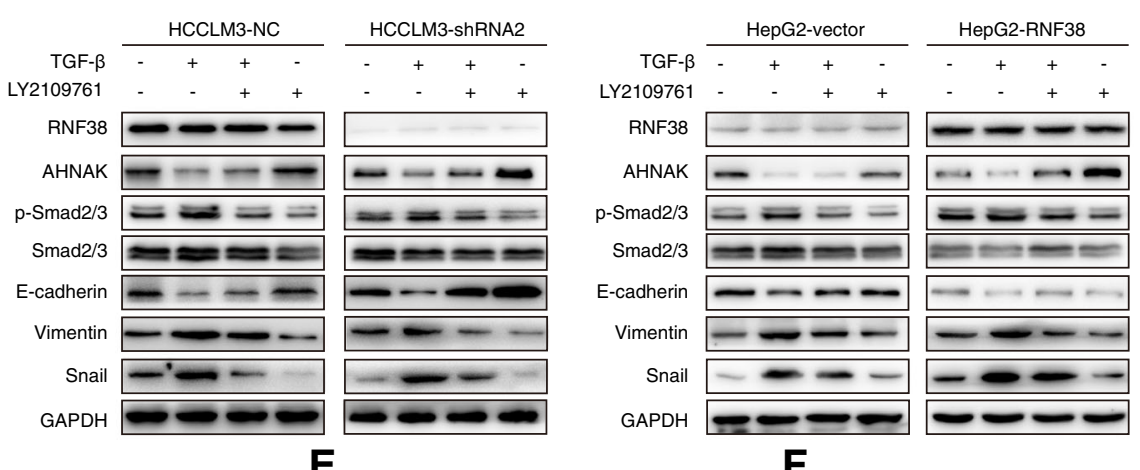

D

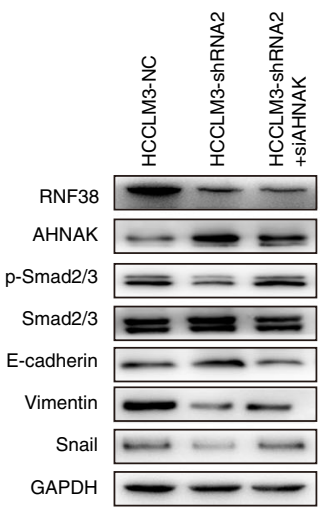

E

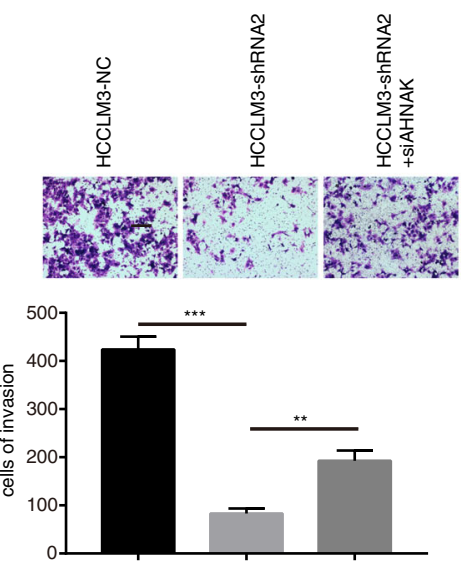

$\mathbf{F}$

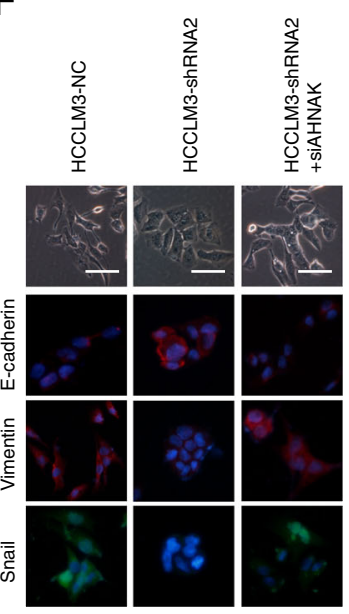

Fig. 5 High level of RNF38 faciliates TGF- $\beta$ pathway by ubiquitinating and degrading AHNAK. a. Western blot showed the phosphorylation level of ERK1/2, AKT, Smad2/3 when the RNF38 was knockdown or overexpression. $\mathbf{b}$. Western blot showed phosphorylation level of Smad2/3 in HCCLM3-NC, HCCLM3-shRNA2, HepG2-vector and HepG2-RNF38 cells treated by (TGF- $\beta, 5$ um) for $0 \mathrm{~h}, 2 \mathrm{~h}, 4 \mathrm{~h}, 8 \mathrm{~h}$. c. The levels of main EMT molecules and p-Smad after TGF- $\beta$ and/or inhibitor incubation. $\mathbf{d}$. The levels of main EMT molecules and p-Smad in HCCLM3 co-transfected NC, shRNF38, siAHNAK. e. Cell migration and invasion of HCCLM3 was inhibited by shRNF38, which was further rescued by AHNAK suppression. f. The cell EMT was inhibited via knockdown RNF38, and rescued by the consequential downregulation of AHNAK in HCCLM3 cells. The shape of cancer cells and EMT markers were showed. Scale bars 100 um

correlational analysis showed that no correlation between RNF38 and TGFBR1 expression at either the protein $(R=0.1006, p=0.72$; Fig. $7 \mathrm{~b})$ or mRNA level $(R=-0.1754, p=0.53$; Fig. $7 \mathrm{~d})$. Moreover, we randomly chose the 102 of 200 patients and validated the expression of RNF38, TGFBR1, and AHNAK by IHC. The results revealed that both RNF38 and AHNAK were present in the cytoplasm of HCC cells, and that positive TGFBR1 staining was mainly localized in the membrane and cytoplasm of cancer cells (Fig. 7e). The correlation between RNF38 and TGFBR1 protein expression in these patients was analyzed via a scatter plot, the results suggested that there was no significant correlation between RNF38 and TGFBR1 expression $(p=0.55, \mathrm{R}=$ 


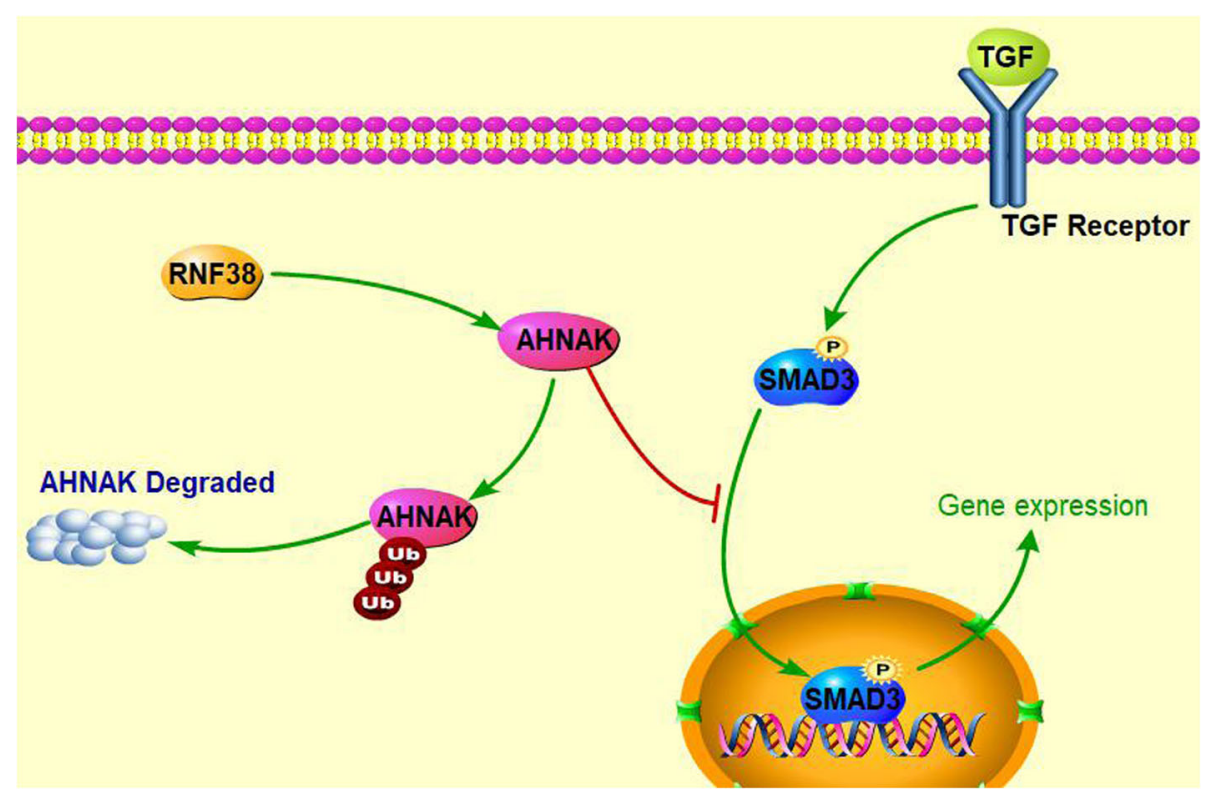

Fig. 6 Model of high level of RNF38 on TGF- $3 /$ Smad signaling. RNF38 overexpression ubiquitinate and degrade AHNAK, which inhibit the p-Smad enteintor the nucleus

0.05938, Fig. 7F). Unexpectedly, patients with high levels of both RNF38 and TGFBR1 exhibited a trend of poor prognoses (Group 1, patients with both RNF38 and TGFBR1 high $(n=31)$. Group 2 , patients with either RNF38 or TGFBR1 high $(n=46)$, Group 3, patients with both RNF38 and TGFBR1 low $(n=25)$. (Fig. $7 \mathrm{~g})$. In addition, the expression of RNF38 significantly correlated with the expression of AHNAK (Additional file 8: Figure S4A). The scatter plot revealed a significant inverse correlation between the relative IOD values for RNF38 and AHNAK (Additional file 8: Figure S4B), indicating that the higher the RNF38 expression was, the lower AHNAK density. Furthermore, the 5-year OS and recurrence curve indicated that the AHNAK-high group $(n=54)$ had a higher rate of survival and a lower rate of recurrence than the AHNAK-low group $(n=48) .(p=0.02, p=0.03$, respectively. Additional file 8: Figure S4B). Additionally, we divided the patients into three groups according to positive staining intensity in our previous study [20]: Group 1 comprised patients with low RNF38 and high AHNAK $(n=30)$. Group 2, patients with RNF38 and AHNAK expression either both low or both high, Group 3, patients with high RNF38 and low AHNAK expression $(n=36)$. Then, we investigated the impact of combined RNF38 and AHNAK expression on survival and recurrence. Group 3 had the lowest overall survival rate $(33.9 \%$ vs 67.5 and $83.4 \%)$ and highest recurrence rate $(75.9 \%$ vs 70.5 and $39.0 \%)$ than others group (33.9\% vs 67.5 and $83.4 \%$, Additional file 8: Figure S4C and 4D). In conclusion, coexpression of RNF38 and TGFBR1 is an independent prognostic parameter for OS and cumulative recurrence.

\section{Discussion}

HCC is a cancer with high invasion and metastasis potential, which contributes to the low survival rate of HCC patients. In the present study, we identified RNF38 as a novel driver in HCC progression via the induction of EMT. First, we discovered that RNF38 expression was elevated in HCC tissues and that a high level of RNF38 was positively associated with the HCC malignant phenotype in a large sample of clinical specimens. Next, we revealed via an experimental approach combining SILAC and co-IP that RNF38, an E3 ligase, regulated AHNAK protein expression. Moreover, we demonstrated that high levels of RNF38 powerfully regulate TGF- $\beta$ signaling. Finally, we showed that RNF38 combined with TGFBR1 expression was an independent predictor of recurrence and survival in HCC patients. The intricate signaling network orchestrated by TGF- $\beta$ signaling to modulate the different stages of HCC indicated that RNF38 might play a unique role in the molecular pathogenesis of HCC.

Here, we provided sufficient evidence to demonstrate that RNF38 promotes HCC progression; notably, cells with high levels of RNF38 tended to exhibit the mesenchymal phenotype both in vitro and in vivo. Combined with the report that the mutation of RNF38 has been found in hepatitis B virus-positive HCC cells based on a cDNA microarray assay [32], our results indicate that RNF38 might promote HCC progression via diverse mechanisms. Furthermore, as an E3 ligase, RNF38 may have complex biological functions due to its diverse substrates. We combined SILAC and co-IP with transcriptome analysis to show that RNF38 functions by the 
A

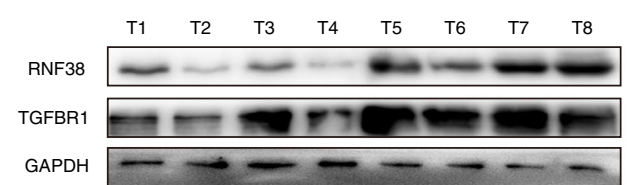

C

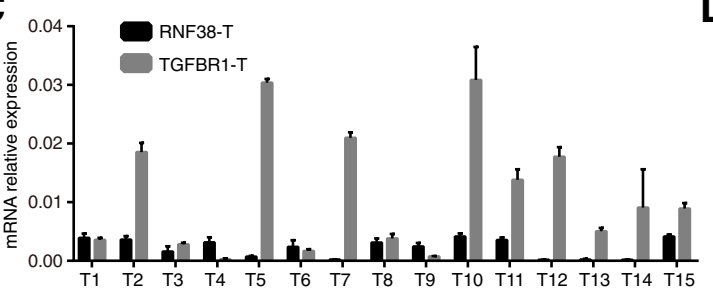

B

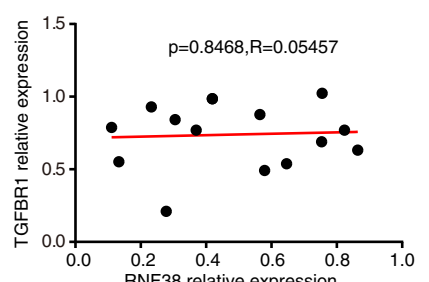

D

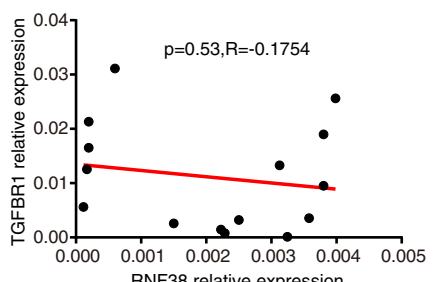

E
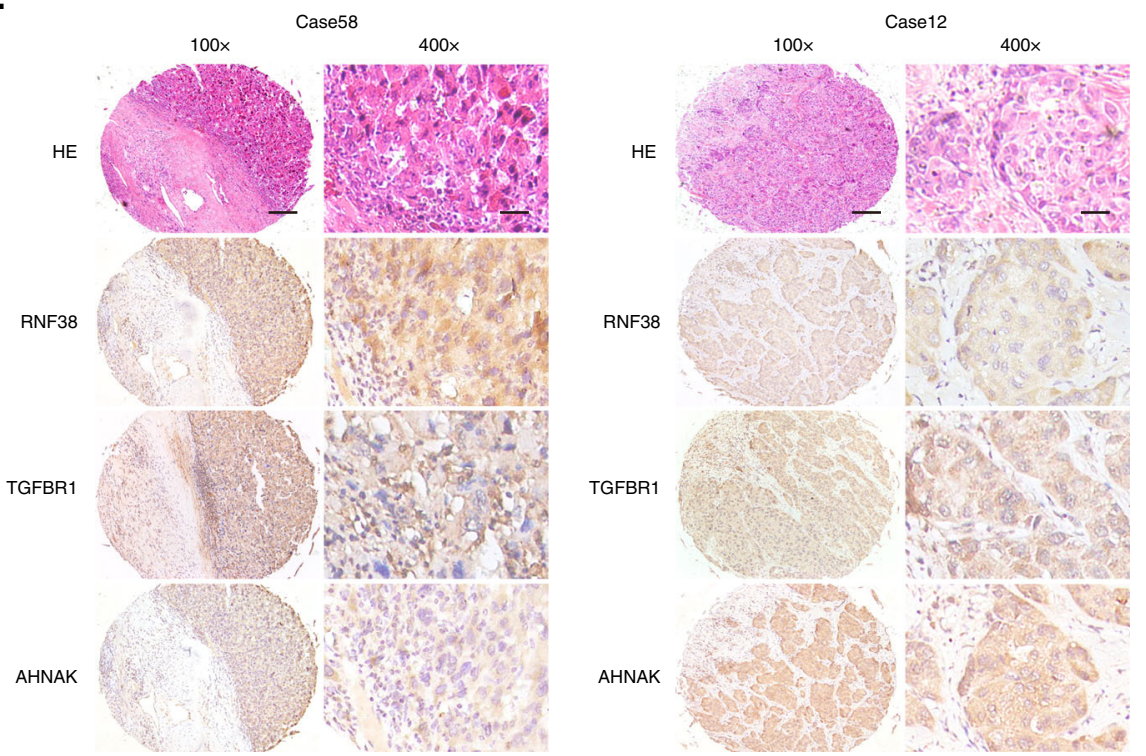

F

G
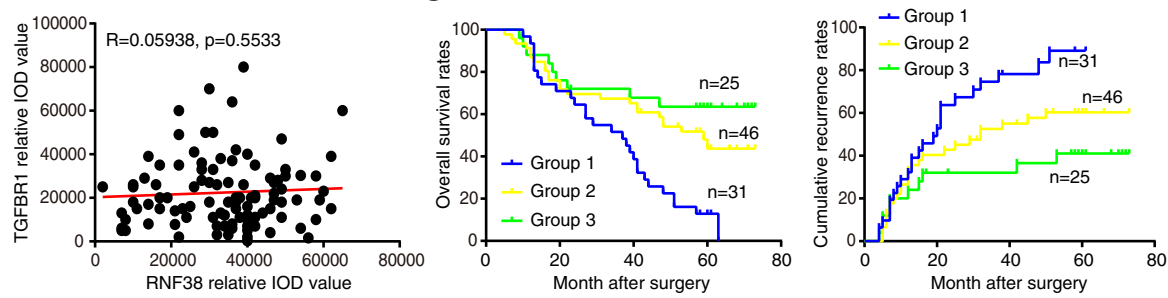

Fig. 7 The RNF38/TGFBR1 complex is an independent factor predicting the prognosis of HCC patients. a. The protein expression of RNF38 and TGFBR1 in 15 HCC tumor tissue were detected through western blot, and the representative images were shown. $\mathbf{b}$. A positive correlation between two proteins were observed in tumor tissues at the protein. c. The mRNA expression of RNF38 and TGFBR1 in 15 HCC tumor tissue were detected through GRT-PCR. The representative image was shown. $\mathbf{d}$. there is no correlation between the two proteins were detected in tumor tissues at the mRNA level. e. Representative immunostaining images of RNF38, AHNAK and TGFBR1. f. Percentage of specimens showing low or high expression of TGFBR1 in 102 HCC tissues, respectively, with low and high of RNF38 expression. And their relationship was assessed by Pearson correlation coefficient g. HCC patients with high RNF38 and high TGFBR1 had the most unfavorable prognosis including the OS and recurrence. Group 1, patients of RNF38 high and TGFBR1 high $(n=31)$. Group 2, patients of RNF38 and TGFBR1 low or high $(n=46)$, Group 3, patients of RNF38 low and TGFBR1 low ( $n=25)$

ubiquitylation of AHNAK, which is a protein belonging to the AHNAK family that consists of two giant proteins [33]. Although AHNAK was originally revealed to be involved in promyelocytic leukemia [34], it is currently known to be related to solid tumor development. For instance, AHNAK negatively regulates cell growth via 
TGF- $\beta$ signaling as a tumor suppressor in breast cancer [28]. Recently, a report suggested that the knockdown of AHNAK in a melanoma cell line led to the loss of cadherin-1 and was associated with poor patient outcomes [29], providing evidence that upregulated RNF38 induced a reduction in E-cadherin levels rather than directly interacting with E-cadherin. The results of the present study revealed that AHNAK acts as a tumor suppressor that is ubiquitinated by RNF38 at the protein level but is not affected at the mRNA level. These findings offer novel insight into the inactivation of this tumor suppressor. Furthermore, the correlation analysis indicated a strong negative correlation between RNF38 and AHNAK protein levels in tumor tissues from HCC patients. Clinically, the RNF38/AHNAK complex predicted poor outcomes of HCC patients. Thus, we concluded that a high level of RNF38 might strongly promote HCC.

The TGF- $\beta$ evokes an intricate signaling network in HCC progression [35], and the dysfunction of this signaling network leads to early-stage HCC [36]. A dual character of the TGF- $\beta$ pathway in tumors has long been recognized, and a deep comprehension of the mechanistic basis and clinical relevance of TGF- $\beta$ signaling is required. Here, using RNA interference and pharmacologic approaches, we provided solid evidence that the overexpression of RNF38 contributes to HCC cell EMT through facilitating TGF- $\beta$ signaling by the ubiquitination of AHNAK. Thus, we identified a novel player in TGF- $\beta$ signaling that disables the tumor-suppressive arm of this pathway. Indeed, we consistently found that RNF38 interference downregulated Smad2/3 phosphorylation to inhibit cellular responses to TGF- $\beta 1$. By combining these findings with those of studies indicating the tumor-promoting effects of increased RNF38 expression in clinical and animal models, we conclude that the level of RNF38 modulates cell responsiveness to TGF- $\beta$, thus playing an important role in HCC development.

\section{Conclusion}

RNF38 is overexpressed in HCC, and RNF38 upregulation endowed HCC cells with the EMT phenotype by facilitating TGF- $\beta$ signaling via ubiquitinating and degrading AHNAK. Therefore, RNF38 could be a novel marker for poor prognosis in HCC patients and a potential therapeutic strategy for HCC.

\section{Additional files}

Additional file 1: Supplementary methods and materials and figure legends. (DOCX $19 \mathrm{~kb}$ )

Additional file 2: Table S1. Antibodies resource (DOCX $15 \mathrm{~kb}$ )

Additional file 3: Figure S1. Analysis RNF38 mRNA level in gastrointestinal tumor vs. normal tissues. A-D. RNF38 mRNA level was up- regulated in colon cancer, gastric cancer, and liver cancer, compared to normal tissues (All data retrieved from www.oncomine.org). (PDF $114 \mathrm{~kb}$ )

Additional file 4: Figure S2. Confocal microscopy images of RNF38 and AHNAK. Shown are HCCLM3-NC cells (blue, DAPI; green, RNF38; red, AHNAK). Scale: $2000 \times$. (PDF $113 \mathrm{~kb}$ )

Additional file 5: Figure S3. The AHNAK expression in HCCLM3 and HCCLM3-siAHNAK cells. Western blot showed that the expression of AHNAK after transfecting the short interfering RNA to HCCLM3. (PDF $152 \mathrm{~kb}$ )

Additional file 6: Figure S4. Clinical relevance of RNF38 and/or AHNAK expression. A. The correlation between RNF38 and AHNAK were assessed by the Pearson correlation. B. RNF38 and AHNAK IOD relative value of 102 patients had negative correlation. C. HCC patients with low AHNAK had the lowest survival rate and the highest recurrence rate. D. HCC patients with high RNF38 and low AHNAK had the most unfavorable prognosis including the OS and recurrence. Group 1, patients of RNF38 low and AHNAK high $(n=30)$. Group 2, patients of both RNF38 and AHNAK low or high $(n=36)$, Group 3, patients of RNF38 high and AHNAK low $(n=36)$. (PDF $132 \mathrm{~kb})$

Additional file 7: Table S2. SILAC of differential proteins in HepG2RNF38 and HepG2-vector (Up-regulated) (DOCX $43 \mathrm{~kb}$ )

Additional file 8: Table S3. SILAC of differential proteins in HepG2RNF38 and HepG2-vector (Down-regulated) (DOCX $37 \mathrm{~kb})$

\section{Abbreviations}

AHNAK: Neuroblast Differentiation-Associated Protein; CML: Chronic myelogenous leukemia; EMT: Epithelial-mesenchymal transition; HCC: Hepatocellular carcinoma; OS: Overall survival; qRT-PCR: Real-Time Quantitative polymerase chain reaction; RNF: RING finger protein; SILAC: Stable isotope labeling with amino acids in cell culture; Smad: Drosophila mothers against decapentaplegic protein; TGF$\beta$ : Transforming growth factor- $\beta$; TMA: Tissue microarray

\section{Acknowledgments}

We all thank Mr. jianwen Hu and Mrs. airu Zhu, Shanghai Bioprofile Technology Company Ltd., for helping our co-IP assays and supporting in SILAC mass spec analysis.

\section{Funding}

This work was funded by the National Natural Science Foundation of China (81302100, 81672825, 81472840, 81502526, 81871909 and 81702861). Cancer Biology State Key Laboratory Project (CBSKL201717) and the Outstanding Clinical Discipline Project of Shanghai Pudong (PWYgy2018-02).

\section{Availability of data and materials}

All data and materials during this study are included in this published article.

\section{Authors' contributions}

Rui $P$ and Peng-Fei Z performed the experiments. Xiao-Yong H, Jia-Bin C, JiaCheng L, Chao G, Hai-Xiang S, Qiang G, Dou-Sheng B analyzed the data. Jia F, Guo-Ming S, Ai-Wu K designed the research. Rui P, Peng-Fei Z, Xuan Y,

Chuan-Yuan W prepared and revised the manuscript and other files. All authors read and approved the final manuscript.

\section{Ethics approval and consent to participate}

This study was approved by the ethics committee of the Shanghai Zhongshan Hospital of Fudan University.

\section{Consent for publication}

All of HCC patients in the study have given their consent to publish their individual data.

\section{Competing interests}

The authors declare that they have no competing interests.

\section{Publisher's Note}

Springer Nature remains neutral with regard to jurisdictional claims in published maps and institutional affiliations. 


\section{Author details}

${ }^{1}$ Liver Cancer Institute, Zhongshan Hospital, Fudan University; Key Laboratory of Carcinogenesis and Cancer Invasion (Fudan University), Ministry of Education, 180 Feng lin Road, Shanghai 200032, People's Republic of China. ${ }^{2}$ Clinical Medical College, Yangzhou University, Yangzhou 225009, Jiangsu, China. ${ }^{3}$ Department of Oncology, Shanghai East Hospital, Tongji University School of Medicine, Shanghai 200031, China. ${ }^{4}$ Cancer Center, Institutes of Biomedical Sciences, Fudan University, Shanghai 200031, People's Republic of China.

Received: 5 December 2018 Accepted: 18 February 2019 Published online: 05 March 2019

\section{References}

1. Siegel RL, Miller KD, Jemal A. Cancer statistics, 2018. CA Cancer J Clin. 2018;68:7-30.

2. Zhou J, Sun H-C, Wang Z, Cong W-M, Wang J-H, et al. Guidelines for diagnosis and treatment of primary liver Cancer in China (2017 edition). Liver Cancer. 2018;7:235-60.

3. Bruix J, Qin S, Merle P, Granito A, Huang YH, et al. Regorafenib for patients with hepatocellular carcinoma who progressed on sorafenib treatment (RESORCE): a randomised, double-blind, placebo-controlled, phase 3 trial. Lancet. 2017;389:56-66.

4. Sia D, Villanueva A, Friedman SL, Llovet JM. Liver Cancer cell of origin, molecular class, and effects on patient prognosis. Gastroenterology. 2017; 152:745-61.

5. Buetow L, Huang DT. Structural insights into the catalysis and regulation of E3 ubiquitin ligases. Nat Rev Mol Cell Biol. 2016;17:626-42.

6. Rape M. Ubiquitylation at the crossroads of development and disease. Nat Rev Mol Cell Biol. 2018;19:59-70.

7. Senft D, Qi J, Ronai ZA. Ubiquitin ligases in oncogenic transformation and cancer therapy. Nat Rev Cancer. 2018;18:69-88.

8. Borden $\mathrm{KL}$, Freemont PS. The RING finger domain: a recent example of a sequence-structure family. Curr Opin Struct Biol. 1996:6:395-401.

9. Lipkowitz S, Weissman AM. RINGs of good and evil: RING finger ubiquitin ligases at the crossroads of tumour suppression and oncogenesis. Nat Rev Cancer. 2011;11:629-43.

10. Giannakis M, Hodis E, Jasmine Mu X, Yamauchi M, Rosenbluh J, et al. RNF43 is frequently mutated in colorectal and endometrial cancers. Nat Genet. 2014;46:1264-6.

11. Ong CK, Subimerb C, Pairojkul C, Wongkham S, Cutcutache I, et al. Exome sequencing of liver fluke-associated cholangiocarcinoma. Nat Genet. 2012; 44:690-3.

12. Eisenberg I, Hochner H, Levi T, Yelin R, Kahan T, et al. Cloning and characterization of a novel human gene RNF38 encoding a conserved putative protein with a RING finger domain. Biochem Biophys Res Commun. 2002:294:1169-76.

13. Humphray SJ, Oliver K, Hunt AR, Plumb RW, Loveland JE, et al. DNA sequence and analysis of human chromosome 9. Nature. 2004;429:369-74.

14. Nacheva EP, Brazma D, Virgili A, Howard-Reeves J, Chanalaris A, et al. Deletions of immunoglobulin heavy chain and $T$ cell receptor gene regions are uniquely associated with lymphoid blast transformation of chronic myeloid leukemia. BMC Genomics. 2010;11:41.

15. Sheren JE, Kassenbrock CK. RNF38 encodes a nuclear ubiquitin protein ligase that modifies p53. Biochem Biophys Res Commun. 2013;440:473-8.

16. Xiong $\mathrm{D}$, Zhu SQ, Wu YB, Jin C, Jiang JH, et al. Ring finger protein 38 promote non-small cell lung cancer progression by endowing cell EMT phenotype. J Cancer. 2018;9:841-50.

17. Peng R, Zhang PF, Zhang C, Huang XY, Ding YB, et al. Elevated TRIM44 promotes intrahepatic cholangiocarcinoma progression by inducing cell EMT via MAPK signaling. Cancer medicine. 2018;7:796-808.

18. Xie N, Cai JB, Zhang L, Zhang PF, Shen YH, et al. Upregulation of B7-H4 promotes tumor progression of intrahepatic cholangiocarcinoma. Cell Death Dis. 2017:8:3205.

19. Peng $R$, Huang $X$, Zhang $C$, Yang $X, X u Y$, et al. Overexpression of UHRF2 in intrahepatic cholangiocarcinoma and its clinical significance. OncoTargets and therapy. 2017;10:5863-72.

20. Cai JB, Shi GM, Dong ZR, Ke AW, Ma HH, et al. Ubiquitin-specific protease 7 accelerates p14(ARF) degradation by deubiquitinating thyroid hormone receptor-interacting protein 12 and promotes hepatocellular carcinoma progression. Hepatology. 2015;61:1603-14.
21. Huang XY, Ke AW, Shi GM, Zhang X, Zhang C, et al. alphaB-crystallin complexes with 14-3-3zeta to induce epithelial-mesenchymal transition and resistance to sorafenib in hepatocellular carcinoma. Hepatology. 2013;57:2235-47.

22. Ong SE, Mann M. A practical recipe for stable isotope labeling by amino acids in cell culture (SILAC). Nat Protoc. 2006;1:2650-60.

23. Brabletz T, Kalluri R, Nieto MA, Weinberg RA. EMT in cancer. Nat Rev Cancer. 2018;18:128-34

24. Zhang Z, Bao M, Lu N, Weng L, Yuan B, et al. The E3 ubiquitin ligase TRIM21 negatively regulates the innate immune response to intracellular doublestranded DNA. Nat Immunol. 2013;14:172-8

25. Rutz S, Kayagaki N, Phung QT, Eidenschenk C, Noubade R, et al. Deubiquitinase DUBA is a post-translational brake on interleukin-17 production in T cells. Nature. 2015;518:417-21.

26. Chuang $\mathrm{CH}$, Greenside PG, Rogers ZN, Brady JJ, Yang D, et al. Molecular definition of a metastatic lung cancer state reveals a targetable CD109Janus kinase-stat axis. Nat Med. 2017;23(3):291-300.

27. Tsai YL, Ha DP, Zhao H, Carlos AJ, Wei S, et al. Endoplasmic reticulum stress activates SRC, relocating chaperones to the cell surface where GRP78/CD109 blocks TGF- $\beta$ signaling. Proc Natl Acad Sci U S A. 2018;115(18):E4245-54.

28. Lee $\mathrm{H}$, Sohn M, Lim HJ, Yoon S, Oh H, et al. Ahnak functions as a tumor suppressor via modulation of TGFbeta/Smad signaling pathway. Oncogene. 2014:33:4675-84.

29. Sheppard HM, Feisst V, Chen J, Print C, Dunbar PR. AHNAK is downregulated in melanoma, predicts poor outcome, and may be required for the expression of functional cadherin-1. Melanoma Res. 2016;26:108-16.

30. Chen B, Wang J, Dai D, Zhou Q, Guo X, et al. AHNAK suppresses tumour proliferation and invasion by targeting multiple pathways in triple-negative breast cancer. J Exp Clin Cancer Res. 2017;36:65.

31. Zhang YE. Non-Smad pathways in TGF-beta signaling. Cell Res. 2009;19:128-39.

32. Xu XR, Huang J, Xu ZG, Qian BZ, Zhu ZD, et al. Insight into hepatocellular carcinogenesis at transcriptome level by comparing gene expression profiles of hepatocellular carcinoma with those of corresponding noncancerous liver. Proc Natl Acad Sci U S A. 2001:98:15089-94.

33. Komuro A, Masuda Y, Kobayashi K, Babbitt R, Gunel M, et al. The AHNAKs are a class of giant propeller-like proteins that associate with calcium channel proteins of cardiomyocytes and other cells. Proc Natl Acad Sci U S A. 2004:101:4053-8.

34. Matza D, Badou A, Kobayashi KS, Goldsmith-Pestana K, Masuda Y, et al. A scaffold protein, AHNAK1, is required for calcium signaling during T cell activation. Immunity. 2008;28:64-74

35. David CJ, Massague J. Contextual determinants of TGFbeta action in development, immunity and cancer. Nat Rev Mol Cell Biol. 2018;19:419-35.

36. Dooley S, Hamzavi J, Ciuclan L, Godoy P, Ilkavets I, et al. Hepatocyte-specific Smad7 expression attenuates TGF-beta-mediated fibrogenesis and protects against liver damage. Gastroenterology. 2008;135:642-59.

Ready to submit your research? Choose BMC and benefit from:

- fast, convenient online submission

- thorough peer review by experienced researchers in your field

- rapid publication on acceptance

- support for research data, including large and complex data types

- gold Open Access which fosters wider collaboration and increased citations

- maximum visibility for your research: over $100 \mathrm{M}$ website views per year

At BMC, research is always in progress.

Learn more biomedcentral.com/submission 